\title{
Genomic profile analysis of diffuse-type gastric cancers
}

\author{
Yeon-Su Lee ${ }^{1 \dagger}$, Yun Sung $\mathrm{Cho}^{2 \dagger}$, Geon Kook Lee ${ }^{3 \dagger}$, Sunghoon Lee ${ }^{2 \dagger}$, Young-Woo Kim ${ }^{4}$, Sungwoong Jho ${ }^{2}$, \\ Hak-Min Kim², Seung-Hyun Hong ${ }^{1}$, Jung-Ah Hwang ${ }^{1}$, Sook-young Kim', Dongwan Hong ${ }^{1}$, II Ju Choi ${ }^{4}$, \\ Byung Chul Kim², ${ }^{2,}$ Byoung-Chul Kim², Chul Hong Kim ${ }^{5}$, Hansol Choi ${ }^{2}$, Youngju Kim³ ${ }^{3}$ Kyung Wook Kim³ ${ }^{3}$ Gu Kong ${ }^{6}$, \\ Hyung Lae Kim ${ }^{7}$, Jong Bhak ${ }^{2,5,8,9^{*}}$, Seung Hoon Lee ${ }^{10^{*}}$ and Jin Soo Lee
}

\begin{abstract}
Background: Stomach cancer is the third deadliest among all cancers worldwide. Although incidence of the intestinal-type gastric cancer has decreased, the incidence of diffuse-type is still increasing and its progression is notoriously aggressive. There is insufficient information on genome variations of diffuse-type gastric cancer because its cells are usually mixed with normal cells, and this low cellularity has made it difficult to analyze the genome.

Results: We analyze whole genomes and corresponding exomes of diffuse-type gastric cancer, using matched tumor and normal samples from 14 diffuse-type and five intestinal-type gastric cancer patients. Somatic variations found in the diffuse-type gastric cancer are compared to those of the intestinal-type and to previously reported variants. We determine the average exonic somatic mutation rate of the two types. We find associated candidate driver genes, and identify seven novel somatic mutations in $\mathrm{CDH}$ 1, which is a well-known gastric cancer-associated gene. Three-dimensional structure analysis of the mutated E-cadherin protein suggests that these new somatic mutations could cause significant functional perturbations of critical calcium-binding sites in the EC1-2 junction. Chromosomal instability analysis shows that the MDM2 gene is amplified. After thorough structural analysis, a novel fusion gene TSC2-RNF216 is identified, which may simultaneously disrupt tumor-suppressive pathways and activate tumorigenesis.
\end{abstract}

Conclusions: We report the genomic profile of diffuse-type gastric cancers including new somatic variations, a novel fusion gene, and amplification and deletion of certain chromosomal regions that contain oncogenes and tumor suppressors.

\section{Background}

Stomach cancer ranks as the third most important cause of global cancer mortality [1]. Histopathologically, gastric cancer (GC) can be classified into two categories based on morphological differences: intestinal-type GC (IGC) and diffuse-type GC (DGC) [2,3]. IGC is typically associated with Helicobacter pylori infection, and is especially common in Japan and Korea [4-6]. DGC is uniformly distributed geographically, and includes aggressive clinical forms,

\footnotetext{
*Correspondence: jongbhak@genomics.org; nslsh@ncc.re.kr

${ }^{\dagger}$ Equal contributors

${ }^{2}$ Personal Genomics Institute, Genome Research Foundation, 443-270 Suwon, Republic of Korea

${ }^{10}$ Research Institute and Hospital, National Cancer Center, Goyang-si, Gyeonggi-do, Republic of Korea

Full list of author information is available at the end of the article
}

such as linitis plastica, which have poor prognosis, especially in young patients $[7,8]$. Genomic DNA modifications leading to $\mathrm{GC}$ can happen as a result of several environmental risk factors such as a high-salt diet and tobacco smoking [9]. Although the incidence of IGC has decreased steadily over several decades (44\% reduction from 1978 to 2005), DGC increased rapidly (by 62\%) from 1978 up to 2000, before decreasing slightly in 2001-2005 [10]. Despite the cumulative evidence that IGC and DGC develop via different carcinogenic pathways [11,12], detailed genomic scale data for DGC are lacking because of limited availability of clinical samples and a low level of purity of the cancer cell population.

To date, very few genes associated with GC subtypes have been identified. The $C D H 1$ gene, which encodes the E-cadherin protein, are the best-known genes associated with hereditary DGC (HDGC) [13-16]. Genetic screening 
for these mutations has been suggested in order to diagnose early-onset GC [17]. E-cadherin dysfunction, caused by mutations, loss of heterozygosity, and promoter hypermethylation, is the most well-established defect in GC initiation and development [18-20]. A genome-wide association study showed that polymorphisms in the prostate stem cell antigen gene (PSCA) are strongly associated with susceptibility to DGC [21]. The microarraybased method, however, is limited to single nucleotide variations, and cannot detect copy-neutral structural variations (SVs). Two recent studies reported on GC exomes, and showed that mutations in the ARID1A gene are frequently detected in GC with microsatellite instability, and in Epstein-Barr virus (EBV)-positive GCs [22,23]. No analysis of GC subtypes was performed, and the majority of the samples analyzed in the studies were from patients with IGC.

Next-generation sequencing (NGS) has allowed researchers to detect disease-associated variations, and helped uncover the underlying mechanisms of disease development. In particular, whole genome sequencing (WGS) can detect most genomic variations, including SVs, such as intrachromosomal and interchromosomal rearrangements. Alternatively, whole exome sequencing (WES), a captured-target sequencing method, can be used for high-depth sequencing of a large number of samples at a relatively low cost [24], although only single nucleotide variations (SNVs) and small insertions or deletions (indels) can be identified using this method. WGS and WES each have advantages and disadvantages, and a number of recent studies have used both methods [25-27].

Here we present detailed characterization of DGC genomes from matched tumor and normal samples by generating whole genomic profiles followed by WES. We used blood samples as a normal control, as in previous studies [28-31]. In order to find DGC-specific variations, IGC genomes were also analyzed and compared with variations identified in genomes of DGCs. Three-dimensional protein structure analysis was performed for novel somatic mutations of the $C D H 1$ gene, and this identified critical regions that were functionally altered by the mutations. In addition, we found a novel fusion gene that could be involved in tumorigenesis.

\section{Results and discussion}

\section{Whole genome and exome sequencing}

Tumor and matched normal (blood) samples from 14 patients with DGC (the clinicopathological characteristics of these patients are shown in Table S1 in Additional file 1), who were all relatively young (median age 38 years) Korean women, were sequenced using an Illumina HiSeq 2000, which produced paired-end, 90-base and 101-base DNA reads. Additionally, five pairs of tumor and matched normal samples from patients with IGC (median age
42 years) were subjected to DNA sequencing; one of these samples was identified later as a case of microsatellite instability (MSI) and hence was excluded from the mutation analysis. None of the samples had any familial history of cancer, and the subtypes were histopathologically confirmed. Only tumor cells were collected by macrodissection after hematoxylin staining.

For the whole genome analysis, on average, 92 gigabases $(\mathrm{Gb})$ per sample were produced at approximately 32 times sequencing depth, reaching 3.5 terabases $(\mathrm{Tb})$ in total, and were mapped to the reference genome (NCBI build 37, hg19) at a mapping rate greater than 94.5\% (for sequencing statistics, see Additional file 1: Table S2). Using the final 3.3 Tb of mapped reads, a genomic profile database was constructed for detecting SNVs, copy number variations (CNVs), and SVs. Because the cellular purity of a tumor sample is a critical feature in cancer genome analysis, it was evaluated using an inhouse calculation method (see Materials and Methods; see Additional file 1: Table S3 and Figure S1). Although we tried to collect only tumor cells, our samples still showed a high level of stromal admixture. To increase the accuracy of mutation detection in genic regions even in low-purity samples, additional WES was performed at approximately 103 times sequencing depth on average, which produced a total of $17 \mathrm{~Gb}$ sequence data. The captured WES covered $93.1 \%$ of the genic region at 10 times or greater depth, and this coverage is similar to that of previously reported exome data on GC [22,23].

Combining the WGS and WES data, we detected somatic alterations in the DGC samples, and compared them with the IGC alterations (the data are summarized in Figure 1 as a circus diagram). To verify our data, we combined and analyzed them with previously reported exome data from two different studies (24 IGC and 5 DGC samples, not including MSI and mixed samples) $[22,23]$ and from array comparative genome hybridization (CGH) data (16 IGC and 14 DGC samples) [32]. Although those studies used mainly IGCs and included only a small number of DGC samples, they could be complementary to our data as a control (by providing an increased number of IGC data and elimination of tissue specificity). In the combined dataset, we compared the differences in alterations between the DGC and IGC samples.

\section{Identification of diffuse-type-specific SNVs and indels}

In each sample pair, we identified approximately 3.7 million SNVs, which were verified using single nucleotide polymorphism (SNP) chips (average concordance rate: 99.2\%; see Additional file 1: Table S4), and approximately 0.69 million indels (for details, see Additional file 1: Table S5 and Table S6). We first assessed mutational frequency of both types of GC at the single nucleotide level (see Additional file 1: Figure $\mathrm{S} 2 \mathrm{a}, \mathrm{b})$. The somatic mutation spectrum was 




Figure 1 Whole genome distribution of somatic mutations and duplication or deletion events in diffuse-type gastric cancers (DGCs). All the somatic mutations, including duplication/deletion events, which were found in the 14 DGC genomes, are merged in the circus plot. From outside to inside, the plot presents the following characteristics: chromosome ideograms, frequency of cumulative amplification or deletion events (black, amplification; red, deletion), and the number of somatic non-synonymous single nucleotide variations (nsSNVs), indels, and SNVs in splice sites for each gene. Black triangles indicate highly mutated genes. Orange triangles denote oncogenes, and blue triangles indicate the tumor suppressors.

dominated by $\mathrm{C}>\mathrm{T}(\mathrm{G}>\mathrm{A})$ transitions in both the DGC and IGC samples, and there were no significant differences in mutational contexts between the two GC types, in accordance with previous studies of GC $[23,30]$. When we analyzed two previously reported exome datasets, we found that the spectrum of the nucleotide substitution ratio was similar to our data (see Additional file 1: Figure S2c, d).

Although the mutation spectrum of DGC is similar to that of IGC, individual mutations in affected genes were different. By subtracting mutations found in normal blood genomes, we identified 922 non-synonymous SNVs (nsSNVs) as somatic mutations in the 18 tumor samples (see Additional file 1: Table S7; see Additional file 2). The average mutation rate of the 18 GCs (1.97 mutations/ $\mathrm{Mb})$ was comparable with that reported in other studies on colon, pancreatic, and liver cancers [33-35]. Of 847 mutated genes affected by the $922 \mathrm{nsSNVs}, 581$ were in 14 DGC cases, 288 were in 4 IGC cases, and 22 (2.6\%) were common to both types. The MSI sample, which was excluded from the comparative analysis, showed approximately six times more SNVs and indels than did the other samples; this result is in agreement with a previous report [22]. When we combined the two previously reported exome datasets, we identified 967 and 2,077 somatic nsSNVs in 19 DGCs and 28 IGCs, respectively. The somatic mutation rate of the IGCs (3.71 mutations/Mb in the 28 samples) was higher than that of the DGCs (2.29 mutations/ $\mathrm{Mb}$ in the 19 samples) (see Additional file 1: Table S8). Previously published research suggests that melanoma and lung cancer have high mutation rates, owing to the involvement of potent mutagens [36]. Likewise, it is possible that IGC has this high mutation rate because its tumorigenic mechanism may be associated more with environmental and/or parasitic mutagens compared with DGC.

For individual variations, putative cancer-causative genes were predicted by driver gene score calculation (see Additional file 1: Table 1 and Table S9). The CDH1 gene was found to be abundantly mutated in DGC 
Table 1 Top candidate driver genes in $\mathbf{1 4}$ diffuse-type gastric cancers

\begin{tabular}{lcccccc}
\hline Gene & Samples, $\mathbf{n}$ & nsSNVs, $\mathbf{n}$ & SNVs in splice site, $\mathbf{n}$ & Indels, $\mathbf{n}$ & $\boldsymbol{P}$-value & Driver gene score \\
\hline PIK3CA & 5 & 5 & 0 & 0 & $3.63 \times 10^{-12}$ & 9.83 \\
CDH1 & 5 & 4 & 1 & 1 & $4.64 \times 10^{-10}$ & 8.02 \\
SNRPN & 2 & 2 & 0 & 0 & $1.86 \times 10^{-07}$ & 5.60 \\
TP53 & 2 & 2 & 0 & 0 & $4.88 \times 10^{-07}$ & 5.36 \\
CMKLR1 & 2 & 2 & 0 & 0 & $5.33 \times 10^{-07}$ & 5.36 \\
CYP2A7 & 2 & 2 & 0 & 0 & $1.53 \times 10^{-06}$ & 4.99 \\
GUCY1B3 & 2 & 2 & 0 & 0 & $1.97 \times 10^{-06}$ & 4.99 \\
PAPOLB & 2 & 2 & 0 & 0 & $2.15 \times 10^{-06}$ & 4.99 \\
MYH9 & 3 & 3 & 0 & 0 & $2.27 \times 10^{-06}$ & 4.99 \\
FAM71B & 1 & 2 & 0 & 0 & $2.51 \times 10^{-06}$ & 4.99 \\
C10Orf90 & 2 & 2 & 0 & 0 & $3.76 \times 10^{-06}$ & 4.86 \\
AKAP8 & 2 & 2 & 0 & 0 & $4.59 \times 10^{-06}$ & 4.81 \\
ZC3H12B & 2 & 2 & 0 & 0 & $5.87 \times 10^{-06}$ & 4.74 \\
SFTA3 & 1 & 1 & 0 & 0 & $6.86 \times 10^{-06}$ & 4.70 \\
SENP7 & 2 & 2 & 0 & 0 & 0 & $7.65 \times 10^{-06}$
\end{tabular}

For additional driver gene lists, see Additional file 1: Table S9.

Table $2 \mathrm{CDH} 1$ alterations in 18 gastric cancers

\begin{tabular}{|c|c|c|c|}
\hline Sample & Type & Alteration & $C D H 1$ region \\
\hline D-01 T & CNV & Loss & Exons 1 to 16 \\
\hline \multirow[t]{2}{*}{$\mathrm{D}-02 \mathrm{~T}$} & SNV & N256S & Exon 6 \\
\hline & CNV & Loss & Exons 1 to 16 \\
\hline $\mathrm{D}-03 \mathrm{~T}$ & SNV & Splice site & Donor site of Intron 4 \\
\hline $\mathrm{D}-04 \mathrm{~T}$ & CNV & Loss & Exons 1 to 16 \\
\hline \multirow[t]{2}{*}{ D-05 T } & SNV & $\mathrm{D} 257 \mathrm{~N}$ & Exon 6 \\
\hline & INS & S829fs & Exon 16 \\
\hline \multirow[t]{2}{*}{$\mathrm{D}-09 \mathrm{~T}$} & SNV & V252G & Exon 6 \\
\hline & SV & Break point & Intron 2 \\
\hline $\mathrm{D}-10 \mathrm{~T}$ & CNV & Loss & Exons 1 to 16 \\
\hline $\mathrm{D}-11 \mathrm{~T}$ & CNV & Loss & Exons 1 to 16 \\
\hline $\mathrm{D}-12 \mathrm{~T}$ & SNV & Q23* & Exon 2 \\
\hline \multirow[t]{2}{*}{$\mathrm{D}-13 \mathrm{~T}$} & CNV & Loss & Exons 1 to 16 \\
\hline & SV & Break point & Introns 2 and 10 \\
\hline $\mathrm{D}-14 \mathrm{~T}$ & SV & Break point & Introns 2, 5 and 9 \\
\hline $\mathrm{I}-01 \mathrm{~T}$ & CNV & Loss & Exons 1 to 16 \\
\hline $\mathrm{I}-02 \mathrm{~T}$ & CNV & Loss & Exons 1 to 16 \\
\hline \multirow[t]{2}{*}{ I-03 T } & SNV & $\mathrm{D} 221 \mathrm{G}$ & Exon 5 \\
\hline & SV & Break point & Introns 10 and 13 \\
\hline I-04 T & CNV & Loss & Exons 1 to 16 \\
\hline
\end{tabular}

CNV, copy number variation; INS, small insertion; SNV, single nucleotide variation; SV, structural variation.
$\left(P=1.29 \times 10^{-2}\right)$, including six somatic mutations (three missense, one nonsense, one frameshift, and one splice site mutations) that have not been reported previously, whereas only one missense mutation was found in the IGC samples (Table 2). All seven CDH1 somatic mutations were verified by Sanger sequencing (see Additional file 1: Table S10 and Table S11). In our DGC samples, $35.7 \%$ (5/14) had CDH1 somatic mutations, and it has been reported that the frequencies of $C D H 1$ somatic mutations in sporadic DGCs can vary from 3\% to greater than $50 \%$ [19,37-40]. It was verified that in countries with a high incidence of sporadic GC (such as Japan and Korea), the frequency of germline mutations in familial GCs is low compared with that in low-incidence countries $[41,42]$. Therefore, we speculate that the overall GC incidence is also related to the frequency of $C D H 1$ somatic mutations. Additionally, one germline mutation (T340A) in $C D H 1$ was found in both tumor and corresponding blood genomes from two samples (D-14, DGC; M-01, MSI-type). Although T340A is a causative mutation in HDGC [43], these two patients did not have any familial history such as GC or lobular breast cancer. Two previous reports analyzing exome data of GC did not identify CDH1 as a highly ranked gene (only one missense mutation in an MSI IGC sample) [22,23]. This discrepancy may be due to the small number of samples of DGC in those studies (2 out of 22 and 3 out of 15 samples were DGCs, respectively). In the present work, PIK3CA and TP53, well-known cancer-associated genes, were the most 
frequently mutated genes in both DGC and IGC see Table 1 and Table S9 in Additional file 1. Mutations in two known PIK3CA hotspots (E545K and H1047L) were found in four DGC samples. Additionally, one nsSNV mutation (Q546K) adjacent to the E545K mutation was found in one DGC sample. In total, 5 out of 14 DGC samples (approximately 30\%) harbored nsSNVs in PIK3CA, which is an oncogene whose mutated form exhibits increased kinase activity, causing cancer cell proliferation [44]. We then compared the low frequency $(16-17 \%)$ of the nsSNVs in PIK3CA in reports by others [22,23,44] (who mostly used IGC samples) and the results of our combined analysis $(31.5 \%$ for DGC, $14.3 \%$ for IGC) (see Additional file 1: Table S9). It appears that the relatively high mutation rates of PIK3CA in DGC may reflect the specificity of mutations in this gene to this type of cancer. Additionally, three samples (two DGC and one IGC) contained both nsSNV and a copy loss of TP53, indicating a homozygous loss of function in TP53, as previously reported [45]. An SNP in the PSCA gene (rs2976329) has been reported to be associated with increased risk of DGC in Japanese and Korean populations [21]. This SNP was also enriched in the majority of DGC samples in our study, (9 out of 14 patients), indicating that our analyzed samples represent typical patients with DGC in East Asia. Additionally, a nonsense mutation (R1446*) in the ARID1A gene, was found in one DGC sample (D-08). Although mutations in ARID1A are frequently detected in MSI and in EBV-positive GCs [22,23], the D-08 sample showed no EBV infection, and an MSI sample (M-01) did not have any ARID1A gene mutations either. From variations in candidate driver genes, $88 \mathrm{nsSNVs}, 4$ small indels, and 2 SNVs in a splice site were verified using conventional Sanger sequencing. Seven of these mutations could not be tested because of PCR failure, and of the remaining 87 mutations, $96.6 \%$ were confirmed as true somatic mutations (see Additional file 1: Table S10 and Table S11).

The somatic variations were then mapped onto the Kyoto Encyclopedia of Genes and Genomes (KEGG) pathways database. This analysis revealed that the mutated genes of DGCs were significantly associated with the calcium signaling pathway $\left(P=7.00 \times 10^{-5}\right.$; see Additional file 1: Table S12 and Table S13). Low calcium intake may contribute to GC development [46]. Calcium is essential for the function of E-cadherin, and a loss of E-cadherinmediated adhesion is involved in the transition from a benign lesion to invasive metastatic cancer [47]. Furthermore, the somatic mutations were strongly associated with pathways related to small cell lung cancer $\left(P=1.00 \times 10^{-6}\right.$ in DGC and $P=4.24 \times 10^{-2}$ in IGC). In particular, genes involved in focal adhesion pathways, such as ITGA, PIK3CA, and PTEN, were frequently mutated.

\section{SV and CNV analysis}

SVs were detected based on discordantly mapped read pairs, and any SVs that were present in the patients' germline genomes were excluded. On average, we found 552 somatic SVs per DGC sample pair (211 large insertions, 264 large deletions, 27 inversions, 44 intrachromosomal translocations, and 6 interchromosomal translocations). We found 664 somatic SVs in each IGC sample pair (285 large insertions, 283 large deletions, 34 inversions, 38 intrachromosomal translocations, and 24 interchromosomal translocations) (for details for each sample, see Additional file 1: Table S14 and Figure S3). Additionally, we found 2,258 genes to be impaired, and 1,736 of these were found only in the DGC samples (for data for each sample, see Additional file 1: Table S15; and see Additional file 3). Three tumor suppressor genes FHIT, WWOX, and MIPOL1, which were reported in a previous GC study [30], had impairments due to the SVs (FHIT in 11 samples, WWOX in 5 samples, and MIPOL 1 in 3 samples).

Fusion genes generated by a chromosomal rearrangement were also analyzed, and 19 fusion gene candidates were identified (see Additional file 1: Table S16), including a novel fusion gene, TSC2-RNF216, found in one sample (Figure 2a, b). TSC2 encoding the tuberin protein was previously suggested as a tumor suppressor gene involved in the mammalian target of rapamycin (mTOR) pathway $[48,49]$. In addition, RNF216, encoding E3 ubiquitin-protein ligase, is involved in cytokine function by preventing the sustained activation of nuclear factor (NF) $-\kappa B$ [50]. The Rap GTPase activating protein (Rap-GAP) domain of the TSC2 protein, which is related to the intrinsic GTPase activity of the Ras-related proteins RAP1A and RAB5, was broken by this chromosomal translocation (Figure 2c). In addition, the zinc finger domains of the RNF216 protein were not expressed in the fusion gene, because of a frameshift that caused premature termination. Using reverse transcription polymerase chain reaction (RT-PCR) followed by sequencing analysis, the expression of this fusion gene in the patient's tissue was confirmed. After testing an additional set of 15 GC patient tissues, we identified 2 patients expressing the fusion gene (Figure 2d, e). This chromosomal translocation can lead to altered cellular behavior both by disrupting the normal functioning of the gene and causing expression of the fusion gene product, which may compete against the normal gene. The fusion gene can competitively interfere with tumor suppressor pathways and activate NF-kB-mediated cytokine signaling.

In DGCs, chromosomes 16, 17, 19, 20, 21, and 22 contained an increased amount of block deletions, while chromosomes 3, 7, 8, and 13 showed notably increased duplications (Figure 1). Many tumor suppressor genes, such as CDH1, PLA2G2A, RUNX3, SMAD2, and TP53, are located in extensively deleted chromosomal regions. 


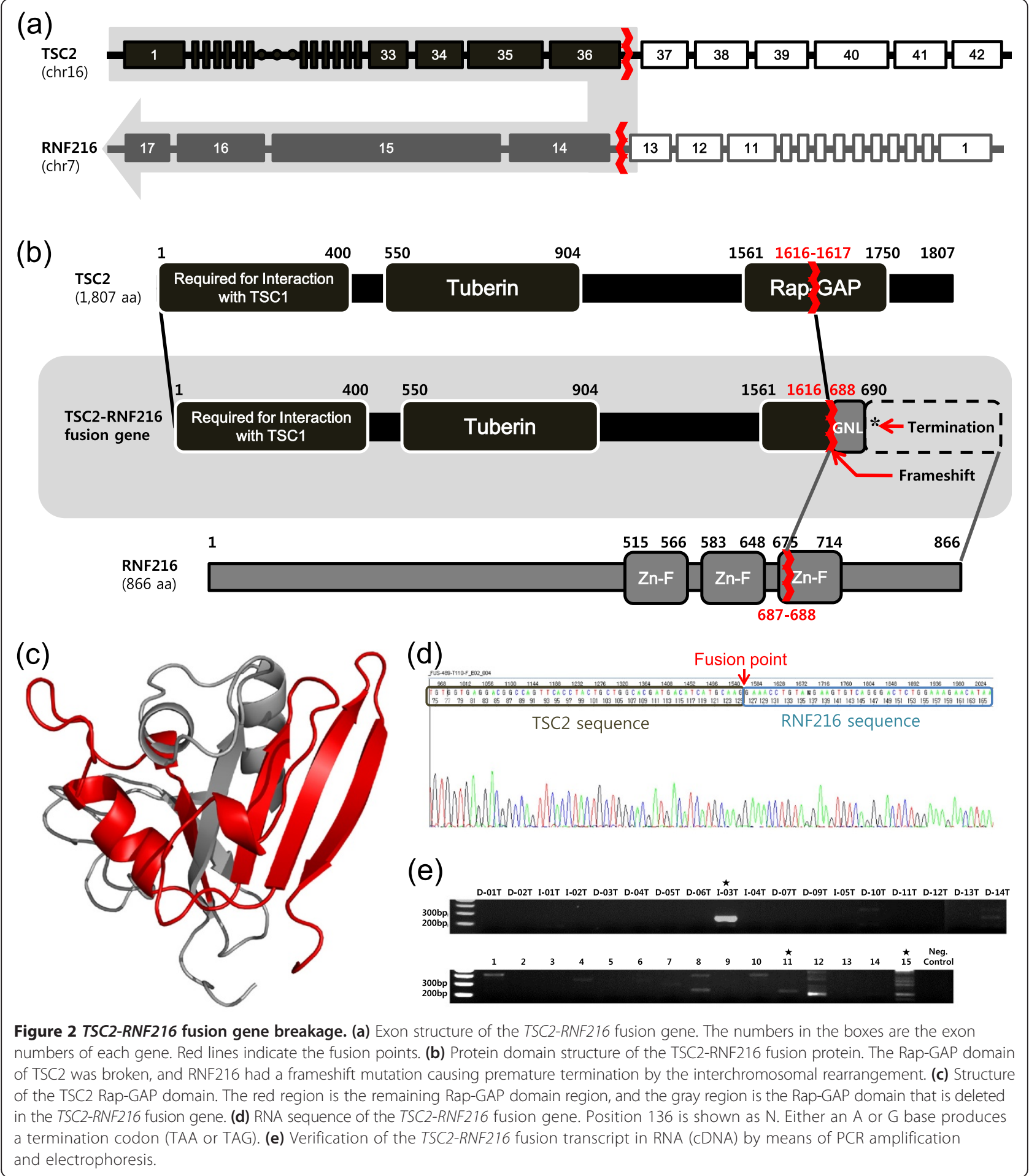

Notably, somatic mutation (nsSNV or splice site mutation) and copy number loss of $C D H 1$ were generally mutually exclusive: four out of five DGC samples with somatic mutation did not have gene copy number losses, and eight out of nine DGC samples with a CDH1 gene copy number loss did not have any somatic mutations in
CDH1. Only one sample $(1 / 18,5.6 \%)$ had both alterations (mutation and copy number loss) concomitantly, and this observation coincides with previous studies reporting that concomitant alterations in $C D H 1$ are rare $[19,40,51,52]$. When we considered SVs in CDH1 together, we found that other three samples had a mutation/copy 
number loss concomitant with SV. Additionally, the copy numbers of the oncogene $M Y C$ were increased in five DGC samples (see Additional file 4), and copy numbers of $M E T$ were increased in three DGC samples [53]. The oncogenes MOS and ZHX2 also showed a copy number gain in five and four DGC samples, respectively. More than half of the samples (10 out of 18) showed a copy number reduction of ARID1A, which is a driver gene for ovarian clear cell carcinoma, and a chromatin remodeler in GC $[22,54,55]$. It is known that the majority of GCs with ARID1A mutations show lower protein expression compared with GCs without an ARID1A mutation [22]. If the dosage effect is important in these cancer tissues, copy number reduction of ARID1A could be a possible cancer-associated factor.
A large region of chromosome 12 was amplified in three DGC genomes; of these three genomes, samples D-01 T and D-02 T showed distinctively high amplification (Figure 3a). The duplication patterns were slightly different: D-01 $\mathrm{T}$ had a tandem duplication of $3 \mathrm{Mbp}$, whereas D-02 $\mathrm{T}$ had an inverted duplication of $1 \mathrm{Mbp}$ (Figure 3b, c). Part of this duplicated region encodes the murine double minute $(M D M 2)$ gene. It was reported that in a small dataset, the $M D M 2$ gene was frequently amplified [56], and that this gene is associated with several cancers [57]. MDM2 overexpression caused by the gene amplification was experimentally confirmed using quantitative RT-PCR with the tumor and adjacent normal tissue paired samples used for NGS analyses, and normal

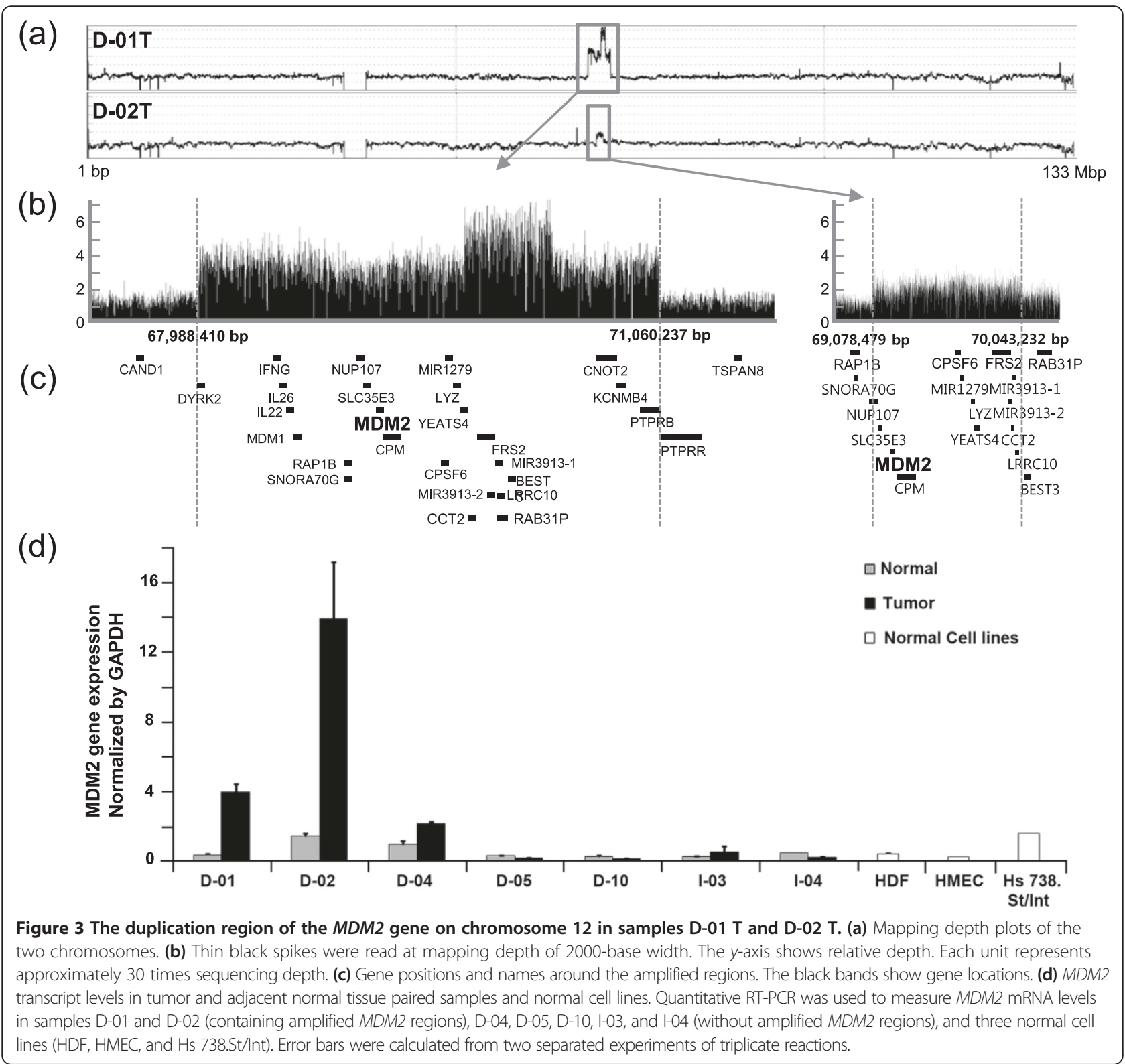


cell lines were included for comparison (Figure 3d). $M D M 2$ overexpression positively correlated with the copy number analysis data. Although previously reported array CGH data [32] had relatively low resolution for $\mathrm{CNV}$ detection, we used those data to search for a bias in alterations of gene copy number in each histopathological type. A copy number gain of genes encoding calcium channel proteins (CACNG6, CACNG7, and CACNG8, $P=4.24 \times 10^{-2}$ ) was significantly more common in DGC samples (see Additional file 1: Table S17). All integrated alteration information is shown in Additional files (see Additional file 1: Table S18 and Table S19; see Additional file 5).

\section{D structural analysis of mutated $\mathrm{CDH} 1$}

To understand how the detected mutations affect protein structure/function and activation of downstream biological pathways influencing carcinogenesis, we analyzed three-dimensional (3D) structures of the mutant E-cadherin protein found in one IGC and five DGC samples (see Additional file 2). The $C D H 1$ gene encodes a calcium-dependent cell adhesion glycoprotein and has five extracellular cadherin domains (EC1-EC5) (Figure 4a). It is known that the interaction between cadherin and calcium is required for dimerization, structural rigidity, and protection from proteolytic degradation [58]. Mutations in the EC1-2 and EC2-3 junctions are known to cause

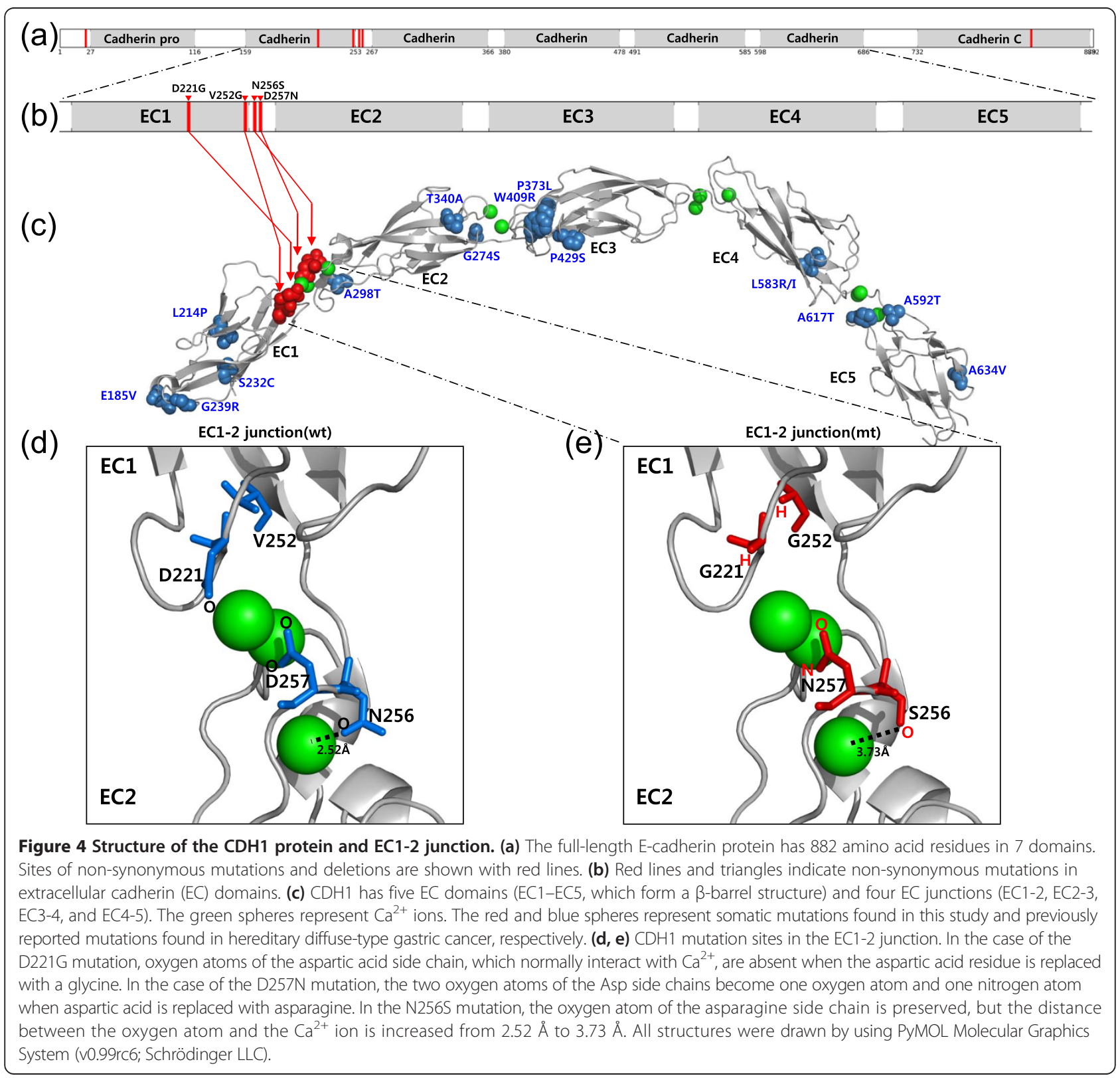


improper cadherin localization and diminished cell adhesion [59]. Structural analysis was carried out on four nsSNVs (D221G, V252G, N256S, and D257N), excluding a nonsense SNV (Q23*), a frameshift insertion (S829fs), and a splice site (chr16:68842472) mutation. All four nsSNVs were located in the junction between EC1 and EC2 (EC1-2 junction) (Figure 4b, c), and three nsSNVs (D221G, N256S, and D257N) were in the protein region that directly interacts with a calcium ion (Figure $4 \mathrm{~d}$, e). This situation could result in anomalous interactions between the cadherin domains. It is reported that A298T, D231K, and D231A mutations, which have a similar structural position at the EC1-2 junction to the somatic mutations found in this study, showed a loss of cell adhesion function $[60,61]$. Another nsSNV mutation, V252G, is located in the $\beta$-sheet structure of cadherin, and its side chain is oriented towards the interior. Because $\beta$ barrel structures generally contain alternating polar and hydrophobic amino acids, with the hydrophobic residues oriented toward the interior of the barrel to form a hydrophobic core, and the polar residues oriented toward the outside of the barrel on the solvent-exposed surface, the formation of the hydrophobic core may be hindered by the V252G mutation (Figure 4e). A previous exome study reported two $C D H 1$ mutations, P127fs (frameshift mutation in a DGC) and V694I (in an MSI IGC) [22]. Dimerization of two cadherin molecules in either a cis or trans configuration occurred at the junction between EC1-2 and EC1-2 [62], whereas mutations at the EC3-4 and EC4-5 junctions did not significantly affect cell adhesion [59]. Val694 is located in a loop region between the EC5 $\beta$-barrel and a transmembrane region distant from the EC1-2 and EC2-3 junctions. Accordingly, the V694I mutation may not be disruptive to E-cadherin protein function. Moreover, Val and Ile have a similar hydrophobic side chain and are similar in size.

Additionally, we structurally analyzed previously reported 19 missense mutations in $C D H 1$ (see Additional file 1; Table S20), which were found in hereditary DGC [60,63-65]. We found that the in vitro functional changes by the missense mutations corresponded exactly to the effects on calcium interaction and structural integrity as described above. The somatic mutations that we found were concentrated in the EC1-2 junction region, whereas the 19 germline mutations were scattered throughout the E-cadherin protein (Figure 4c). This finding coincides with previous results that germline $C D H 1$ mutations are not restricted to specific E-cadherin domains, but are distributed throughout all protein functional domains [66]. In this study, we identified four somatic missense mutations in exons 5 and 6 , and it is known that somatic $C D H 1$ mutations found in sporadic DGCs cluster in exons 7 to $10[66,67]$. Exons 5 and 6 encode the structural components of EC1, EC2, and EC1-2 junction, as in the case of exons 7 and 8. Taken together, these results suggest that $C D H 1$ somatic mutations in the EC1-2 junction that disrupt cell adhesion function are prevalent in DGCs, and thus that dysfunction of the EC1-2 junction is specific to DGC.

\section{Conclusions}

WGS and WES were used here to identify somatic variations that are characteristic of DGC. The samples contained both DGC and normal cells, such that the sample purity range was as low as $20 \%$ according to our genomic profile analyses. Our approach (WGS combined with exome data with sequencing depth of greater than 120 times) resulted in accurate detection of SNVs and indels in genic regions. The efficacy of this approach is evident in the verification data, which showed a positive rate of 96.6\% for somatic SNVs and indels. This combination approach also has the benefit of detecting SVs and largescale abnormalities, whereas WES alone can identify only somatic variations such as SNVs and indels in exonic regions. This strategy may facilitate analysis of heterogeneous cancer cells, an important issue in cancer genomics [68].

To the best of our knowledge, this is the first extensive genomic analysis of DGC. We identified somatic SNVs and indels in the DGC samples, compared with the IGC samples. We also found SVs and a novel fusion gene in GC samples, although their functional effects need to be validated in further studies. $C D H 1$ mutations are known to be prevalent in several types of cancers: gastric, colorectal, breast, thyroid, and ovarian. E-cadherin dysfunction is the most well-established defect in GC development, and our data support its importance in DGC. The DGC samples showed a high frequency of somatic mutations in $C D H 1$, and protein structural analysis suggested that the mutations influence the interaction between E-cadherin and calcium, and the stability of $\beta$-barrel structures of cadherin. These results indicate that $C D H 1$ and the calcium signaling pathway are associated with the pathogenesis of DGC. Our data from GC genomes should improve the understanding of the mechanism via which protein structural perturbations can cause pathological changes and possibly lead to cancer development. This knowledge may help to diagnose and treat GCs in a more individualized manner, taking into account the different subtypes.

\section{Materials and methods}

\section{Patients and specimen collection}

This study was performed in accordance with the Declaration of Helsinki and was approved by the local ethics committee of the National Cancer Center (IRB No. NCCNCS10-392). Signed informed consent was obtained from all participants before enrolment.

GC specimens and peripheral blood samples were collected from 18 patients (14 with DGC and 4 with IGC) who 
had undergone surgical resection at the National Cancer Center, South Korea, between 2005 and 2010 (see Additional file 1: Table S1). Tumor and adjacent normal specimens were examined by pathologists to remove the necrotic region and the intervening tissue, in accordance with the World Health Organization histopathological criteria. After pathological examination, the samples were snap-frozen and stored in liquid nitrogen until genomic DNA extraction.

\section{Nucleic acid preparation}

The frozen tumor samples were macro-dissected and lightly stained with hematoxylin to identify regions consisting of $80 \%$ or more cancer cells. Genomic DNA was extracted with the MagAttract DNA Blood Midi Kit (Qiagen Inc, Valencia, CA, USA), in accordance with the manufacturer's protocol. DNA quality was assessed using a Nanodrop spectrometer (Nanodrop Technologies, Wilmington, DE, USA). Control DNA from matched peripheral blood samples was processed in the same manner. The same frozen tumor samples were used for total RNA extraction using a Qiagen RNeasy Mini Kit (Qiagen). Quality of total RNA was assessed with Lab-on-a-Chip on an Agilent 2100 Bioanalyzer (Aglient Technologies, Santa Clara, CA, USA). The total RNA $(1 \mu \mathrm{g})$ was used in a reverse transcription reaction with poly (dT) primers using the SuperScriptTMIII FirstStrand Synthesis system (Invitrogen/Life Technologies, Grand Island, NY, USA), in accordance with the manufacturer's instructions. DNA and RNA of adjacent normal tissues were obtained using same methods as tumor samples.

\section{Whole genome sequencing}

Genomic DNA was sheared using Covaris S series (Covaris, MS, USA). The sheared DNA was end-repaired, A-tailed, and ligated to pair-end adapters, in accordance with the manufacturer's protocol (Pair End Library Preparation Kit, Illumina, San Diego, CA, USA). Adapter-ligated fragments were purified and dissolved in $30 \mu \mathrm{l}$ of elution buffer, and $1 \mu \mathrm{l}$ of the mixture was used as a template for 12 cycles of PCR amplification. The PCR product was gel-purified using the QIAquick Gel Extraction Kit (Qiagen). Library quality and concentration were determined using an Agilent 2100 BioAnalyzer (Agilent). Libraries were quantified using a SYBR green qPCR protocol on a LightCycler 480 (Roche, Indianapolis, IN, USA), in accordance with Illumina's library quantification protocol. Based on the qPCR quantification, libraries were normalized to $2 \mathrm{nM}$, and then denatured using $0.1 \mathrm{~N} \mathrm{NaOH}$. Cluster amplification of denatured templates was performed in flow cells, in accordance with the manufacturer's protocol (Illumina). Flow cells were paired-end sequenced on an Illumina HiSeq 2000 using HiSeq Sequencing kits. A base-calling pipeline (Sequencing Control Software (SCS), Illumina) was used to process the raw fluorescent images and the called sequences.

\section{Exome sequencing}

WES was performed using SureSelect Human All Exon $44 \mathrm{Mb}$ (Agilent), following the manufacturer's standard protocol. Briefly, a paired-end DNA sequencing library was prepared through genomic DNA shearing, endrepair, A-tailing, PE adaptor ligation, and amplification. After hybridization of the library with bait sequences for 24 hours, the captured library was purified and amplified with an index barcode tag, and the library quality and quantity were determined. Sequencing of the exome library was carried out using the $100 \mathrm{bp}$ paired-end mode of the HiSeq SBS kit, in accordance with the manufacturer's manual.

\section{Read alignment and variation detection}

Paired-end sequence reads were aligned to the hg19 human reference genome (NCBI build 37) with the BurrowsWheeler Aligner (BWA) [69] (v0.5.9). Two mismatches were permitted in a 45 bp seed sequence. The rmdup command of SAMtools was used to remove PCR duplicates of sequence reads, which can be generated during the library construction process [70]. Aligned reads were realigned at putative indel positions with the Genome Analysis Toolkit (GATK) [71] IndelRealigner algorithm to enhance mapping quality. Base quality scores were recalibrated using the TableRecalibration algorithm of GATK.

\section{SNP and small insertion/deletion analysis and somatic mutation filtering}

Putative SNVs were called and filtered using the UnifiedGenotyper and VariantFiltration commands in GATK. The options used for SNP calling were a read mapping depth of 5 to 200 times with a consensus quality of 20 , and a prior likelihood for heterozygosity value of 0.001 . To obtain small indels, the UnifiedGenotyper DINDEL mode of GATK was used with default values, including a window size of $300 \mathrm{bp}$. To identify somatic mutations in cancer genomes, mutations from cancer genomes were filtered using the mutations from blood genomes. The remaining mutations were filtered again using the mapping status of the blood genomes. At each remaining tumor mutation position, if the minimum mapping depth was at least 3 and the mutation ratio of the blood genome was at least 0.2 , the tumor SNV was discarded. To remove false-positive reads caused by genomic duplications, the somatic mutations were called from uniquely mapped reads. Additionally, mutations located in duplicated sequences ( $\geq 90 \%$ identity) were filtered out if the mutations were not detected by both WGS and WES. The indels were called from reads aligned using the Smith-Waterman algorithm [72]. Two additional databases, dbSNP 131, and an 
internal Korean variation database that contains variations found in 20 healthy Koreans, were used to filter out additional SNVs. All somatic mutations altering amino acid sequences were checked by expert laboratory personnel using the tview command of SAMtools. The same method was applied to call SNVs and small indels from the previously reported exome data, except for the step filtering mutations located in duplicate sequences.

\section{Mutation rate calculation}

For the mutation rate calculation, the number of mutations was compared with the total number of bases in sufficiently covered coding DNA sequence (CDS) regions. The mutations consisted of SNVs and small indels. The sufficiently covered CDS region was defined where its read mapping depth was at least five reads.

\section{Sanger sequencing}

A total of 94 nsSNVs, indels, and SNVs in splice sites were verified by conventional Sanger sequencing using dye-terminator chemistry and analyzed with an automatic sequencer ABI 3730 (Applied Biosystems). The target regions were amplified by PCR followed by direct sequencing, or cloned into TA vectors. At least $20 \mathrm{TA}$ vector clones were sequenced, because mutations in low purity samples are difficult to detect by Sanger sequencing. Details of the PCR and sequencing primers are given (see Additional file 1: Table S11).

\section{Annotation of variations}

Predicted SNVs were compared with NCBI dbSNP (version 131) to annotate known SNP information. Each SNV was mapped on the University of California Santa Cruz (UCSC) gene table by genomic features such as coding region, untranslated region, and intron. Non-synonymous SNV information was extracted by comparing UCSC reference gene information. The KEGG pathway [73] was used to analyze altered protein sets. Information on cancer-related mutations was obtained from COSMIC (Catalogue of Somatic Mutations In Cancer) [74].

\section{Driver gene prediction}

Driver gene scores were calculated using SNVs as described in a previous report [22], with an efficiently covered region with a normal sample mapping depth of 4 times or greater and a cancer sample mapping depth of 3 times or greater. In brief, the driver gene score was calculated by comparing the observed number of nsSNVs with the expected number. The expected number of nsSNVs was calculated from the background non-synonymous to synonymous SNV ratio, and the number of observed synonymous SNVs. The $P$-value for a driver gene score was calculated from the numbers of expected and observed
nsSNVs, assuming that the numbers of nsSNVs had a Poisson distribution.

\section{Purity calculation}

The purity of the cancer samples was determined by calculating the mapping depths ratio of the diploid and the haploid regions of the samples. Cancer samples usually have a mix of diploid and haploid regions, which are generated by heterozygous deletions. The first step is to calculate the ratio of the mapping depths from cancer and normal genomes by scanning the genomes with a window size of $50 \mathrm{~kb}$. If a sample does not contain any tumor cells, there will always be only one peak in a histogram that shows the mapping depth ratio. If there are tumor cells, there will be two or more peaks (see Additional file 1: Figure S1). Secondly, the purity is calculated by the ratio distance(s) between the peaks using the equation shown below.

$$
\operatorname{Purity}(\mathrm{P})=\frac{2\left(\mathrm{R}_{2 n}-\mathrm{R}_{1 n}\right)}{\mathrm{R}_{2 n}}
$$

$R_{2 n}$ is the ratio of the diploid (2N) region, and $R_{1 n}$ is the ratio of the haploid $(1 \mathrm{~N})$ region. When the purity was lower than about 0.5 , the peaks were not distinct. To overcome this ambiguity, somatic deletion regions detected by BreakDancer were used as the $1 \mathrm{~N}$ depth regions [75]. The false-positive somatic deletion regions were filtered out using the deletion regions detected in the blood genomes. When the average depth ratio of the somatic deletion region was greater than that of the depth of the $2 \mathrm{~N}$ region, the deletion was regarded as a false positive.

\section{Identification of copy number variation regions}

CNVs based on the differences in sequencing depths between normal and cancerous samples were detected using BIC-seq [76] v1.1.2 with $\lambda=100$ and bin_size $=$ 1000 bp. Regions with a $\log 2$ ratio smaller than -0.2 or larger than 0.2 were defined as deleted or duplicated regions, respectively. The CNV candidates were mapped to COSMIC [74] data to find cancer-associated genes. For previously reported array CGH data [32], +0.152173 and -0.135797 were applied as thresholds for gain and loss, respectively. Genes having its corresponding clones were used for $\mathrm{CNV}$ analysis.

\section{Identification of structural variants and gene fusions}

SVs were scanned using BreakDancer [75] with score $\geq 80$. A somatic SV was defined as an SV not found in blood samples. We obtained structural variation signals (SVSs), which are clusters composed of more than three uniquely and discordantly mapped read pairs from all SV regions. We used SVSs found only in tumor tissue samples for 
consecutive analysis. We considered two SVSs as equal, if the breakpoints of the two SVSs were $400 \mathrm{bp}$ or closer to each other. SVSs located in intergenic and intron region were excluded. A gene was determined to have a breakage event when an SVS breakpoint occurred within the gene. Gene fusion was defined as a connection of two genes by a SVS. The final gene fusion candidates were selected when the number of supporting read pairs was above 10, and the only interchromosomal gene fusions were chosen.

\section{Structure prediction of $\mathrm{CDH} 1$}

The mutated structure of CDH1 (E-cadherin) was predicted by homology modeling using mouse E-cadherin protein (PDBID:3Q2V) [77] as a template with MODELLER [78] v9.10.

\section{Genome-wide SNP analysis}

SNP genotyping was performed using an Axiom genotyping solution with an Axiom Genome-Wide ASI 1 Array Plate and a reagent kit, in accordance with the manufacturer's protocol (Affymetrix). Briefly, total genomic DNA (200 ng) was treated with $20 \mu \mathrm{l}$ of denaturation buffer and $40 \mu \mathrm{l}$ of neutralization buffer, followed by amplification for 23 hours using $320 \mu \mathrm{l}$ of Axiom amplification mix. Amplified DNA was randomly digested into 25 to125 bp fragments with $57 \mu \mathrm{l}$ of Axiom fragmentation mix at $37^{\circ} \mathrm{C}$ for 30 minutes, followed by DNA precipitation for DNA purification and recovery. DNA pellets were dried and resuspended in $80 \mu \mathrm{l}$ of hybridization master mix, and $3 \mu \mathrm{l}$ of suspended sample was used for sample qualification. A hybridization-ready sample was denaturated by PCR at $95^{\circ} \mathrm{C}$ for 20 minutes and $48^{\circ} \mathrm{C}$ for 3 minutes. The denatured DNA was transferred to a hybridization tray, and loaded onto a GeneTitan MC with an Axiom ASI array plate (Affytmerix). Hybridization continued on the GeneTitan for 24 hours, after which ligation, staining, and stabilization reagent trays were sequentially loaded onto the instrument. GeneTitan was controlled by an Affymetrix GeneChip Command Console GeneTitan Control (Affymetrix). The chip image was scanned with the GeneTitan, and the resulting data, a Image data (DAT) file, was automatically converted to a Cell Intensity data (CEL) file. The CEL intensity file was normalized, and genotype calling was performed using Genotyping Console 4.1 with Axiom GT1 algorithms, in accordance with the manufacturer's manual. The cut-off value for data quality control was a DISHQC of 0.82 or greater for hybridization, and a call rate of $97 \%$ or greater.

\section{MDM2 gene expression analysis by quantitative real-time PCR}

MDM2 mRNA expression was analyzed using a quantitative real-time PCR system, and the MDM2 gene expression was normalized to GAPDH. Primer sequences for $M D M 2$ and GAPDH were as follows. $M D M 2-\mathrm{RT}$ forward sequence was $5^{\prime}$-GGCCTGC TTTACATGTGCAA-3', MDM2-RT reverse sequence was 5'-GCACAATCATTTGAATTGGTTGTC-3', GA $P D H$ forward sequence was 5'-TGCACCACCAACTG CTTA-3', and GAPDH reverse sequence was 5'- GG ATGCAGGGATGATGTTC-3'. Quantitative real-time PCR was performed with SYBR Green I PCR Master Mix (Qiagen) on a LightCycler 480 Real-Time PCR System (Roche). The experiments were performed in triplicate, and the PCR reaction was performed as follows: $5 \mathrm{mi}-$ nutes at $95^{\circ} \mathrm{C}$ for initial denaturation, then 45 cycles at $95^{\circ} \mathrm{C}$ for 10 seconds, $58^{\circ} \mathrm{C}$ for 10 seconds, and $72^{\circ} \mathrm{C}$ for 10 seconds, followed by melting curve analysis at $95^{\circ} \mathrm{C}$ for 5 seconds, $65^{\circ} \mathrm{C}$ for 1 minute, and cooling for 30 seconds at $40^{\circ} \mathrm{C}$. For each reaction, 5 ng of cDNA, $500 \mathrm{nM}$ primer (final concentration) and $5 \mu \mathrm{l}$ of $2 \mathrm{X}$ SYBR Green I PCR Master Mix was used in a $10 \mu \mathrm{l}$ reaction volume.

\section{Fusion gene analysis}

Genomic rearrangement of the fusion gene was verified by PCR using a forward primer located in TSC2 $\left(5^{\prime}-\mathrm{CT}\right.$ CAGGTTCCGAGCCTAACAG-3') and a reverse primer in RNF216 (5'-GCAAACATAGTGAGACCCCATCT-3'). The PCR reaction was performed as follows: 15 minutes at $94^{\circ} \mathrm{C}$ for initial denaturation, then 40 cycles at $94^{\circ} \mathrm{C}$ for 30 seconds, $60^{\circ} \mathrm{C}$ for 30 seconds, and $72^{\circ} \mathrm{C}$ for $1 \mathrm{mi}-$ nute, with 5 minutes at $72^{\circ} \mathrm{C}$ for post-extension. For each reaction, $30 \mathrm{ng} / \mu \mathrm{l} \mathrm{gDNA}, 100 \mathrm{nM}$ primer, and 0.5 $\mathrm{U}$ of Taq polymerase (Qiagen) were used in a $20 \mu \mathrm{l}$ reaction. The expression of a fusion gene in one patient sample was analyzed by RT-PCR using a forward primer located in TSC2 (5'-GAGCATGGCTCCTA CAGGTACAC-3') and a reverse primer in RNF216 (5'-CTCTTCACAGGTGAGGCCATTAT-3'). The RTPCR reaction was performed as follows: 5 minutes at $94^{\circ} \mathrm{C}$ for initial denaturation, then 40 cycles at $94^{\circ} \mathrm{C}$ for 30 seconds, $60^{\circ} \mathrm{C}$ for 30 seconds, and $72^{\circ} \mathrm{C}$ for $1 \mathrm{mi}-$ nute, with 5 minutes at $72^{\circ} \mathrm{C}$ for post-extension. For each reaction, $10 \mathrm{ng}$ cDNA, $200 \mathrm{nM}$ primer, and $0.5 \mathrm{U}$ of Taq polymerase (Solgent, Korea) were used in each $20 \mu \mathrm{l}$ reaction. The RT-PCR products were analyzed by Sanger sequencing using an automatic sequencer (ABI3700; Applied Biosystems) to verify their fusion at the sequence level.

\section{Data access}

The data from this study have been submitted to NCBI Sequence Read Archive (SRA) [79] under accession number SRA057772 (WGS) and SRA057973 (WES). 


\section{Additional files}

\section{Additional file 1: Figures $\mathrm{S} 1$ to $\mathrm{S} 3$ and Tables $\mathrm{S} 1$ to $\mathrm{S} 20$, in portable document format (pdf).}

Additional file 2: Variations in coding region (altering amino acids) and splice site.

\section{Additional file 3: Putative somatic gene breakages by structural} variations.

Additional file 4: Copy number variations.

Additional file 5: Integrated alterations.

\section{Abbreviations}

3D: Three-dimensional; CGH: comparative genome hybridization; CNV: Copy number variation; EBV: Epstein-Barr virus; indel: Insertion or deletion; DGC: diffuse-type gastric cancer; Gb: Gigabase; HDGC: Hereditary diffuse-type gastric cancer; IGC: Intestinal-type gastric cancer; MSI: Microsatellite instability; mTOR: mammalian target of rapamycin; NF: nuclear factor; NGS: Next-generation sequencing; SNP: Single nucleotide polymorphism; nsSNV: Non-synonymous SNV; SNV: Single nucleotide variation; SV: Structural variation; SVS: Structural variation signal; Tb: Terabase; WES: Whole exome sequencing; WGS: Whole genome sequencing.

\section{Competing interests}

The authors declare that they have no competing interests.

\section{Authors' contributions}

SHL and JSL: project leading and study supervision; YSL and JB: study concept and design; YSL, YSC, SL and JB: drafting of the manuscript; SL, YSC, SJ, HMK, BCG, HC and DH: analysis and interpretation of data; BCK and CHK: whole genome and exome sequencing data production; SHH, JAH and SyK: experimental data generation; GK and HLK: project design; GKL, YWK and IJC: clinical support and sample related works; and YK and KWK: sample preparation and analysis. All authors read and approved the final manuscript.

\section{Acknowledgements}

This research was approved by National Cancer Center institutional review board with IRB No. NCCNCS-10-392, Cancer Genome study for GC using Next Generation Sequencing methods. This research was supported by National Cancer Center grant numbers 1110520 and 1011680. The bioinformatic work was supported by a grant from the KRIBB Research Initiative Program. We thank Maryana Bhak for editing, and Dr Cheolju Lee in KIST for providing the normal gastric cell line.

\section{Author details}

${ }^{1}$ Cancer Genomics Branch, Research Institute, National Cancer Center, Goyang-si, Gyeonggi-do, Republic of Korea. ${ }^{2}$ Personal Genomics Institute, Genome Research Foundation, 443-270 Suwon, Republic of Korea. ${ }^{3}$ Department of Pathology and Tumor Tissue Bank, National Cancer Center, Goyang-si, Gyeonggi-do, Republic of Korea. ${ }^{4}$ Gastric Cancer Branch, Research Institute and Hospital, National Cancer Center, Goyang-si, Gyeonggi-do, Republic of Korea. ${ }^{5}$ Theragen $\mathrm{BiO}$ Institute, TheragenEtex, 443-270 Suwon, Republic of Korea. ${ }^{6}$ Department of Pathology, College of Medicine, Hanyang University, Seoul, Republic of Korea. ${ }^{7}$ Department of Biochemistry, School of Medicine, Ewha Womans University, Seoul, Republic of Korea. ${ }^{8}$ Program in Nano Science and Technology, Department of Transdisciplinary Studies, Seoul National University, Suwon 443-270, Republic of Korea. ${ }^{9}$ Advanced Institutes of Convergence Technology Nano Science and Technology, Suwon 443-270, Republic of Korea. ${ }^{10}$ Research Institute and Hospital, National Cancer Center, Goyang-si, Gyeonggi-do, Republic of Korea.

Received: 23 November 2013 Accepted: 1 April 2014 Published: 1 April 2014

\section{References}

1. Ferlay J, Soerjomataram I, Ervik M, Dikshit R, Eser S, Mathers C, Rebelo M, Parkin DM, Forman D, Bray F: GLOBOCAN 2012: Estimated Cancer Incidence, Mortality and Prevalence Worldwide in 2012. http://globocan.iarc.fr.
2. Lauren P: The Two histological main types of gastric carcinoma: diffuse and so-called intestinal-type carcinoma. An attempt at a histo-clinical classification. Acta Pathol Microbiol Scand 1965, 64:31-49.

3. Crew KD, Neugut Al: Epidemiology of gastric cancer. World J Gastroenterol 2006, 12:354-362.

4. Parkin DM, Bray F, Ferlay J, Pisani P: Estimating the world cancer burden: Globocan 2000. Int J Cancer 2001, 94:153-156.

5. Ushijima T, Sasako M: Focus on gastric cancer. Cancer Cell 2004, 5:121-125.

6. Vauhkonen M, Vauhkonen H, Sipponen P: Pathology and molecular biology of gastric cancer. Best Pract Res Clin Gastroenterol 2006, 20:651-674.

7. Rosai J, Ackerman LV: Rosai and Ackerman's Surgical Pathology. 9th edition. St. Louis, Mo. London: Mosby; 2004.

8. Henson DE, Dittus C, Younes M, Nguyen H, Albores-Saavedra J: Differential trends in the intestinal and diffuse types of gastric carcinoma in the United States, 1973-2000: increase in the signet ring cell type. Arch Pathol Lab Med 2004, 128:765-770.

9. Compare D, Rocco A, Nardone G: Risk factors in gastric cancer. Eur Rev Med Pharmacol Sci 2010, 14:302-308.

10. Wu H, Rusiecki JA, Zhu K, Potter J, Devesa SS: Stomach carcinoma incidence patterns in the United States by histologic type and anatomic site. Cancer Epidemiol Biomarkers Prev 2009, 18:1945-1952.

11. Tahara E: Genetic pathways of two types of gastric cancer. IARC Sci Publ 2004, 157:327-349.

12. Nobili S, Bruno L, Landini I, Napoli C, Bechi P, Tonelli F, Rubio CA, Mini E, Nesi G: Genomic and genetic alterations influence the progression of gastric cancer. World J Gastroenterol 2011, 17:290-299.

13. Guilford $P$, Humar B, Blair V: Hereditary diffuse gastric cancer: translation of $\mathrm{CDH} 1$ germline mutations into clinical practice. Gastric Cancer 2010, 13:1-10.

14. Chen Y, Kingham K, Ford JM, Rosing J, Van Dam J, Jeffrey RB, Longacre TA, Chun N, Kurian A, Norton JA: A prospective study of total gastrectomy for CDH1-positive hereditary diffuse gastric cancer. Ann Surg Oncol 2011, 18:2594-2598.

15. Suriano G, Oliveira C, Ferreira P, Machado JC, Bordin MC, De Wever O, Bruyneel EA, Moguilevsky N, Grehan N, Porter TR, Richards FM, Hruban RH, Roviello F, Huntsman D, Mareel M, Carneiro F, Caldas C, Seruca R: Identification of $\mathrm{CDH} 1$ germline missense mutations associated with functional inactivation of the E-cadherin protein in young gastric cancer probands. Hum Mol Genet 2003, 12:575-582.

16. Oliveira C, Senz J, Kaurah P, Pinheiro H, Sanges R, Haegert A, Corso G, Schouten J, Fitzgerald R, Vogelsang H, Keller G, Dwerryhouse S, Grimmer D, Chin SF, Yang HK, Jackson CE, Seruca R, Roviello F, Stupka E, Caldas C, Huntsman D: Germline $\mathrm{CDH} 1$ deletions in hereditary diffuse gastric cancer families. Hum Mol Genet 2009, 18:1545-1555.

17. Corso G, Pedrazzani C, Pinheiro H, Fernandes E, Marrelli D, Rinnovati A, Pascale V, Seruca R, Oliveira C, Roviello F: E-cadherin genetic screening and clinico-pathologic characteristics of early onset gastric cancer. Eur $J$ Cancer 2011, 47:631-639

18. Carneiro P, Figueiredo J, Bordeira-Carriço R, Fernandes MS, Carvalho J, Oliveira C, Seruca R: Therapeutic targets associated to E-cadherin dysfunction in gastric cancer. Expert Opin Ther Targets 2013, 17:1187-1201.

19. Carvalho J, van Grieken NC, Pereira PM, Sousa S, Tijssen M, Buffart TE, Diosdado B, Grabsch H, Santos MA, Meijer G, Seruca R, Carvalho B, Oliveira C: Lack of microRNA-101 causes E-cadherin functional deregulation through EZH2 up-regulation in intestinal gastric cancer. J Pathol 2012, 228:31-44.

20. Carneiro F, Oliveira C, Leite M, Seruca R: Molecular targets and biological modifiers in gastric cancer. Semin Diagn Pathol 2008, 25:274-287.

21. Study Group of Millennium Genome Project for Cancer, Sakamoto $H_{1}$ Yoshimura K, Saeki N, Katai H, Shimoda T, Matsuno Y, Saito D, Sugimura H, Tanioka F, Kato S, Matsukura N, Matsuda N, Nakamura T, Hyodo I, Nishina T, Yasui W, Hirose H, Hayashi M, Toshiro E, Ohnami S, Sekine A, Sato Y, Totsuka H, Ando M, Takemura R, Takahashi Y, Ohdaira M, Aoki K, Honmyo I, et al: Genetic variation in PSCA is associated with susceptibility to diffuse-type gastric cancer. Nat Genet 2008, 40:730-740.

22. Wang K, Kan J, Yuen ST, Shi ST, Chu KM, Law S, Chan TL, Kan Z, Chan AS, Tsui WY, Lee SP, Ho SL, Chan AK, Cheng GH, Roberts PC, Rejto PA, Gibson NW, Pocalyko DJ, Mao M, Xu J, Leung SY: Exome sequencing identifies frequent mutation of ARID1A in molecular subtypes of gastric cancer. Nat Genet 2011, 43:1219-1223.

23. Zang ZJ, Cutcutache I, Poon SL, Zhang SL, McPherson JR, Tao J, Rajasegaran V, Heng HL, Deng N, Gan A, Lim KH, Ong CK, Huang D, Chin SY, Tan IB, Ng CC, 
Yu W, Wu Y, Lee M, Wu J, Poh D, Wan WK, Rha SY, So J, Salto-Tellez M, Yeoh KG, Wong WK, Zhu YJ, Futreal PA, Pang B, et al: Exome sequencing of gastric adenocarcinoma identifies recurrent somatic mutations in cell adhesion and chromatin remodeling genes. Nat Genet 2012, 44:570-574

24. Ng SB, Turner EH, Robertson PD, Flygare SD, Bigham AW, Lee C, Shaffer T, Wong M, Bhattacharjee A, Eichler EE, Bamshad M, Nickerson DA, Shendure J: Targeted capture and massively parallel sequencing of 12 human exomes. Nature 2009, 461:272-276.

25. Imielinski M, Berger AH, Hammerman PS, Hernandez B, Pugh TJ, Hodis E, Cho J, Suh J, Capelletti M, Sivachenko A, Sougnez C, Auclair D, Lawrence MS, Stojanov P, Cibulskis K, Choi K, de Waal L, Sharifnia T, Brooks A, Greulich H, Banerji S, Zander T, Seidel D, Leenders F, Ansén S, Ludwig C, Engel-Riedel W, Stoelben E, Wolf J, Goparju C, et al: Mapping the hallmarks of lung adenocarcinoma with massively parallel sequencing. Cell 2012, 150:1107-1120.

26. Pugh TJ, Morozova O, Attiyeh EF, Asgharzadeh S, Wei JS, Auclair D, Carter SL, Cibulskis K, Hanna M, Kiezun A, Kim J, Lawrence MS, Lichenstein L, McKenna A, Pedamallu CS, Ramos AH, Shefler E, Sivachenko A, Sougnez C, Stewart C, Ally A, Birol I, Chiu R, Corbett RD, Hirst M, Jackman SD, Kamoh B, Khodabakshi AH, Krzywinski M, Lo A, et al: The genetic landscape of high-risk neuroblastoma. Nat Genet 2013, 45:279-284.

27. Banerji S, Cibulskis K, Rangel-Escareno C, Brown KK, Carter SL, Frederick AM, Lawrence MS, Sivachenko AY, Sougnez C, Zou L, Cortes ML, Fernandez-Lopez JC, Peng S, Ardlie KG, Auclair D, Bautista-Piña V, Duke F, Francis J, Jung J, Maffuz-Aziz A, Onofrio RC, Parkin M, Pho NH, Quintanar-Jurado V, Ramos AH, Rebollar-Vega R, Rodriguez-Cuevas S, Romero-Cordoba SL, Schumacher SE, Stransky N, et al: Sequence analysis of mutations and translocations across breast cancer subtypes. Nature 2012, 486:405-409.

28. Chang VY, Federman N, Martinez-Agosto J, Tatishchev SF, Nelson SF: Whole exome sequencing of pediatric gastric adenocarcinoma reveals an atypical presentation of Li-Fraumeni syndrome. Pediatr Blood Cancer 2013, 60:570-574.

29. Berger MF, Lawrence MS, Demichelis F, Drier Y, Cibulskis K, Sivachenko AY, Sboner A, Esgueva R, Pflueger D, Sougnez C, Onofrio R, Carter SL, Park K, Habegger L, Ambrogio L, Fennell T, Parkin M, Saksena G, Voet D, Ramos AH, Pugh TJ, Wilkinson J, Fisher S, Winckler W, Mahan S, Ardlie K, Baldwin J, Simons JW, Kitabayashi N, MacDonald TY, et al: The genomic complexity of primary human prostate cancer. Nature 2011, 470:214-220.

30. Nagarajan N, Bertrand D, Hillmer AM, Zang ZJ, Yao F, Jacques PE, Teo AS, Cutcutache I, Zhang Z, Lee WH, Sia YY, Gao S, Ariyaratne PN, Ho A, Woo XY, Veeravali L, Ong CK, Deng N, Desai KV, Khor CC, Hibberd ML, Shahab A, Rao J, Wu M, Teh M, Zhu F, Chin SY, Pang B, So JB, Bourque G, et al: Whole-genome reconstruction and mutational signatures in gastric cancer. Genome Biol 2012, 13:R115.

31. Lee E, Iskow R, Yang L, Gokcumen O, Haseley P, Luquette $\sqcup$ 3rd, Lohr JG, Harris CC, Ding L, Wilson RK, Wheeler DA, Gibbs RA, Kucherlapati R, Lee C, Kharchenko PV, Park PJ: Cancer Genome Atlas Research Network: landscape of somatic retrotransposition in human cancers. Science 2012, 337:967-971.

32. Tsukamoto $Y$, Uchida T, Karnan S, Noguchi T, Nguyen LT, Tanigawa M, Takeuchi I, Matsuura K, Hijiya N, Nakada C, Kishida T, Kawahara K, Ito H, Murakami K, Fujioka T, Seto M, Moriyama M: Genome-wide analysis of DNA copy number alterations and gene expression in gastric cancer. J Pathol 2008, 216:471-482.

33. Li M, Zhao H, Zhang X, Wood LD, Anders RA, Choti MA, Pawlik TM, Daniel HD, Kannangai R, Offerhaus GJ, Velculescu VE, Wang L, Zhou S, Vogelstein B, Hruban RH, Papadopoulos N, Cai J, Torbenson MS, Kinzler KW: Inactivating mutations of the chromatin remodeling gene ARID2 in hepatocellular carcinoma. Nat Genet 2011, 43:828-829.

34. Jones S, Zhang X, Parsons DW, Lin JC, Leary RJ, Angenendt P, Mankoo P, Carter H, Kamiyama H, Jimeno A, Hong SM, Fu B, Lin MT, Calhoun ES, Kamiyama M, Walter K, Nikolskaya T, Nikolsky Y, Hartigan J, Smith DR, Hidalgo M, Leach SD, Klein AP, Jaffee EM, Goggins M, Maitra A, lacobuzio-Donahue C, Eshleman JR, Kern SE, Hruban RH, et al: Core signaling pathways in human pancreatic cancers revealed by global genomic analyses. Science 2008, 321:1801-1806.

35. Parsons DW, Li M, Zhang X, Jones S, Leary RJ, Lin JC, Boca SM, Carter H, Samayoa J, Bettegowda C, Gallia GL, Jallo Gl, Binder ZA, Nikolsky Y, Hartigan J, Smith DR, Gerhard DS, Fults DW, VandenBerg S, Berger MS, Marie SK, Shinjo SM, Clara C, Phillips PC, Minturn JE, Biegel JA, Judkins AR, Resnick AC, Storm PB, Curran T, et al: The genetic landscape of the childhood cancer medulloblastoma. Science 2011, 331:435-439.
36. Vogelstein B, Papadopoulos N, Velculescu VE, Zhou S, Diaz LA Jr, Kinzler KW: Cancer genome landscapes. Science 2013, 339:1546-1558.

37. Becker KF, Atkinson MJ, Reich U, Becker I, Nekarda H, Siewert JR, Höfler H: $\mathrm{E}$-cadherin gene mutations provide clues to diffuse type gastric carcinomas. Cancer Res 1994, 54:3845-3852.

38. Berx G, Becker KF, Höfler H, van Roy F: Mutations of the human E-cadherin (CDH1) gene. Hum Mutat 1998, 12:226-237.

39. Machado JC, Soares P, Carneiro F, Rocha A, Beck S, Blin N, Berx G, Sobrinho-Simões $\mathrm{M}$ : E-cadherin gene mutations provide a genetic basis for the phenotypic divergence of mixed gastric carcinomas. Lab Invest 1999, 79:459-465.

40. Corso G, Carvalho J, Marrelli D, Vindigni C, Carvalho B, Seruca R, Roviello F, Oliveira C: Somatic mutations and deletions of the E-cadherin gene predict poor survival of patients with gastric cancer. J Clin Oncol 2013, 31:868-875.

41. Carneiro F, Oliveira C, Suriano G, Seruca R: Molecular pathology of familial gastric cancer, with an emphasis on hereditary diffuse gastric cancer. $J$ Clin Pathol 2008, 61:25-30.

42. Oliveira C, Pinheiro H, Figueiredo J, Seruca R, Carneiro F: E-cadherin alterations in hereditary disorders with emphasis on hereditary diffuse gastric cancer. Prog Mol Biol Trans/ Sci 2013, 116:337-359.

43. Kim HC, Wheeler JM, Kim JC, Ilyas M, Beck NE, Kim BS, Park KC, Bodmer WF: The E-cadherin gene (CDH1) variants T340A and L599V in gastric and colorectal cancer patients in Korea. Gut 2000, 47:262-267.

44. Barbi S, Cataldo I, De Manzoni G, Bersani S, Lamba S, Mattuzzi S, Bardelli A, Scarpa A: The analysis of PIK3CA mutations in gastric carcinoma and metanalysis of literature suggest that exon-selectivity is a signature of cancer type. J Exp Clin Cancer Res 2010, 29:32.

45. Ding L, Getz G, Wheeler DA, Mardis ER, McLellan MD, Cibulskis K, Sougnez C, Greulich H, Muzny DM, Morgan MB, Fulton L, Fulton RS, Zhang Q, Wendl MC, Lawrence MS, Larson DE, Chen K, Dooling DJ, Sabo A, Hawes AC, Shen H, Jhangiani SN, Lewis LR, Hall O, Zhu Y, Mathew T, Ren Y, Yao J, Scherer SE, Clerc K, et al: Somatic mutations affect key pathways in lung adenocarcinoma. Nature 2008, 455:1069-1075.

46. Yang CY, Cheng MF, Tsai SS, Hsieh YL: Calcium, magnesium, and nitrate in drinking water and gastric cancer mortality. Jpn J Cancer Res 1998, 89:124-130.

47. Pećina-Slaus N: Tumor suppressor gene E-cadherin and its role in normal and malignant cells. Cancer Cell Int 2003, 3:17.

48. Ma L, Chen Z, Erdjument-Bromage $H$, Tempst P, Pandolfi PP: Phosphorylation and functional inactivation of TSC2 by Erk implications for tuberous sclerosis and cancer pathogenesis. Cell 2005, 121:179-193.

49. Kang YJ, Lu MK, Guan KL: The TSC1 and TSC2 tumor suppressors are required for proper ER stress response and protect cells from ER stress-induced apoptosis. Cell Death Differ 2011, 18:133-144.

50. Miah SM, Purdy AK, Rodin NB, MacFarlane AW 4th, Oshinsky J, Alvarez-Arias DA, Campbell KS: Ubiquitylation of an internalized killer cell lg-like receptor by Triad3A disrupts sustained NF-kappaB signaling. J Immunol 2011, 186:2959-2969.

51. Tamura G, Yin J, Wang S, Fleisher AS, Zou T, Abraham JM, Kong D, Smolinski KN, Wilson KT, James SP, Silverberg SG, Nishizuka S, Terashima M, Motoyama T, Meltzer SJ: E-Cadherin gene promoter hypermethylation in primary human gastric carcinomas. J Natl Cancer Inst 2000, 92:569-573.

52. Machado JC, Oliveira C, Carvalho R, Soares P, Berx G, Caldas C, Seruca R, Carneiro F, Sobrinho-Simöes M: E-cadherin gene (CDH1) promoter methylation as the second hit in sporadic diffuse gastric carcinoma. Oncogene 2001, 20:1525-1528.

53. Seruca R, Suijkerbuijk RF, Gärtner F, Criado B, Veiga I, Olde-Weghuis D, David L, Castedo S, Sobrinho-Simões M: Increasing levels of MYC and MET co-amplification during tumor progression of a case of gastric cancer. Cancer Genet Cytogenet 1995, 82:140-145.

54. Wiegand KC, Shah SP, Al-Agha OM, Zhao Y, Tse K, Zeng T, Senz J, McConechy MK, Anglesio MS, Kalloger SE, Yang W, Heravi-Moussavi A, Giuliany R, Chow C, Fee J, Zayed A, Prentice L, Melnyk N, Turashvili G, Delaney AD, Madore J, Yip S, McPherson AW, Ha G, Bell L, Fereday S, Tam A, Galletta L, Tonin PN, Provencher D, et al: ARID1A mutations in endometriosis-associated ovarian carcinomas. N Engl J Med 2010, 363:1532-1543.

55. Jones S, Wang TL, Shih IM, Mao TL, Nakayama K, Roden R, Glas R, Slamon D, Diaz LA Jr, Vogelstein B, Kinzler KW, Velculescu VE, Papadopoulos N: Frequent mutations of chromatin remodeling gene ARID1A in ovarian clear cell carcinoma. Science 2010, 330:228-231. 
56. Günther T, Schneider-Stock R, Häckel C, Kasper HU, Pross M, Hackelsberger A, Lippert $H$, Roessner A: Mdm2 gene amplification in gastric cancer correlation with expression of Mdm2 protein and p53 alterations. Mod Pathol 2000, 13:621-626.

57. Wade M, Li YC, Wahl GM: MDM2, MDMX and p53 in oncogenesis and cancer therapy. Nat Rev Cancer 2013, 13:83-96.

58. Nagar B, Overduin M, Ikura M, Rini JM: Structural basis of calcium-induced E-cadherin rigidification and dimerization. Nature 1996, 380:360-364.

59. Handschuh G, Luber B, Hutzler P, Hofler H, Becker KF: Single amino acid substitutions in conserved extracellular domains of E-cadherin differ in their functional consequences. J Mol Biol 2001, 314:445-454.

60. Brooks-Wilson AR, Kaurah P, Suriano G, Leach S, Senz J, Grehan N, Butterfield YS, Jeyes J, Schinas J, Bacani J, Kelsey M, Ferreira P, MacGillivray B, MacLeod P, Micek M, Ford J, Foulkes W, Australie K, Greenberg C, LaPointe M, Gilpin C, Nikkel S, Gilchrist D, Hughes R, Jackson CE, Monaghan KG, Oliveira MJ, Seruca R, Gallinger S, Caldas C, et al: Germline E-cadherin mutations in hereditary diffuse gastric cancer: assessment of 42 new families and review of genetic screening criteria. J Med Genet 2004, 41:508-517.

61. Ozawa M, Engel J, Kemler R: Single amino acid substitutions in one Ca2+ binding site of uvomorulin abolish the adhesive function. Cell 1990, 63:1033-1038.

62. Leckband D, Prakasam A: Mechanism and dynamics of cadherin adhesion. Annu Rev Biomed Eng 2006, 8:259-287.

63. Garziera M, De Re V, Geremia S, Seruca R, Figueiredo J, Melo S, Simões-Correia J, Caggiari L, De Zorzi M, Canzonieri V, Cannizzaro R, Toffoli G: A novel CDH1 germline missense mutation in a sporadic gastric cancer patient in north-east of Italy. Clin Exp Med 2013, 13:149-157.

64. Simões-Correia J, Figueiredo J, Lopes R, Stricher F, Oliveira C, Serrano L, Seruca R: E-cadherin destabilization accounts for the pathogenicity of missense mutations in hereditary diffuse gastric cancer. PLOS One 2012, 7:e33783.

65. Suriano G, Mulholland D, de Wever O, Ferreira P, Mateus AR, Bruyneel E, Nelson CC, Mareel MM, Yokota J, Huntsman D, Seruca R: The intracellular E-cadherin germline mutation V832 M lacks the ability to mediate cell-cell adhesion and to suppress invasion. Oncogene 2003, 22:5716-5719.

66. Oliveira C, Suriano G, Ferreira P, Canedo P, Kaurah P, Mateus R, Ferreira A Ferreira AC, Oliveira MJ, Figueiredo C, Carneiro F, Keller G, Huntsman D, Machado JC, Seruca R: Genetic screening for familial gastric cancer. Hered Cancer Clin Pract 2004, 2:51-64.

67. Becker KF, Höfler $\mathrm{H}$ : Frequent somatic allelic inactivation of the $\mathrm{E}$ cadherin gene in gastric carcinomas. J Natl Cancer Inst 1995, 87:1082-1084.

68. Shibata D: Cancer. Heterogeneity and tumor history. Science 2012, 336:304-305.

69. Li H, Durbin R: Fast and accurate short read alignment with Burrows-Wheeler transform. Bioinformatics 2009, 25:1754-1760.

70. Li H, Handsaker B, Wysoker A, Fennell T, Ruan J, Homer N, Marth G, Abecasis G, Durbin R: 1000 Genome Project Data Processing Subgroup: the sequence alignment/map format and SAMtools. Bioinformatics 2009, 25:2078-2079.

71. McKenna A, Hanna M, Banks E, Sivachenko A, Cibulskis K, Kernytsky A, Garimella K, Altshuler D, Gabriel S, Daly M, DePristo MA: The Genome Analysis Toolkit: a MapReduce framework for analyzing next-generation DNA sequencing data. Genome Res 2010, 20:1297-1303.

72. Smith TF, Waterman MS: Identification of common molecular subsequences. J Mol Biol 1981, 147:195-197.

73. Kanehisa M: The KEGG database. Novartis Found Symp 2002, 247:91-101. discussion 101-103, 119-128, 244-252.

74. Bamford S, Dawson E, Forbes S, Clements J, Pettett R, Dogan A, Flanagan A, Teague J, Futreal PA, Stratton MR, Wooster R: The COSMIC (Catalogue of Somatic Mutations in Cancer) database and website. Br J Cancer 2004, 91:355-358

75. Chen K, Wallis JW, McLellan MD, Larson DE, Kalicki JM, Pohl CS, McGrath SD, Wendl MC, Zhang Q, Locke DP, Shi X, Fulton RS, Ley TJ, Wilson RK, Ding L, Mardis ER: BreakDancer: an algorithm for high-resolution mapping of genomic structural variation. Nat Methods 2009, 6:677-681

76. Xi R, Hadjipanayis AG, Luquette LJ, Kim TM, Lee E, Zhang J, Johnson MD, Muzny DM, Wheeler DA, Gibbs RA, Kucherlapati R, Park PJ: Copy number variation detection in whole-genome sequencing data using the Bayesian information criterion. Proc Natl Acad Sci U S A 2011, 108:E1128-E1136.
77. Harrison OJ, Jin X, Hong S, Bahna F, Ahlsen G, Brasch J, Wu Y, Vendome J, Felsovalyi K, Hampton CM, Troyanovsky RB, Ben-Shaul A, Frank J, Troyanovsky SM Shapiro L, Honig B: The extracellular architecture of adherens junctions revealed by crystal structures of type I cadherins. Structure 2011, 19:244-256.

78. Sali A, Potterton L, Yuan F, van Vlijmen H, Karplus M: Evaluation of comparative protein modeling by MODELLER. Proteins 1995, 23:318-326.

79. The sequence read archive. http://www.ncbi.n/m.nih.gov/sra.

doi:10.1186/gb-2014-15-4-r55

Cite this article as: Lee et al:: Genomic profile analysis of diffuse-type gastric cancers. Genome Biology 2014 15:R55.

\section{Submit your next manuscript to BioMed Central and take full advantage of:}

- Convenient online submission

- Thorough peer review

- No space constraints or color figure charges

- Immediate publication on acceptance

- Inclusion in PubMed, CAS, Scopus and Google Scholar

- Research which is freely available for redistribution 